\title{
El impacto de las innovaciones tecnológicas en el Derecho Privado
}

Alfredo F. Soria Aguilar (Compilador)

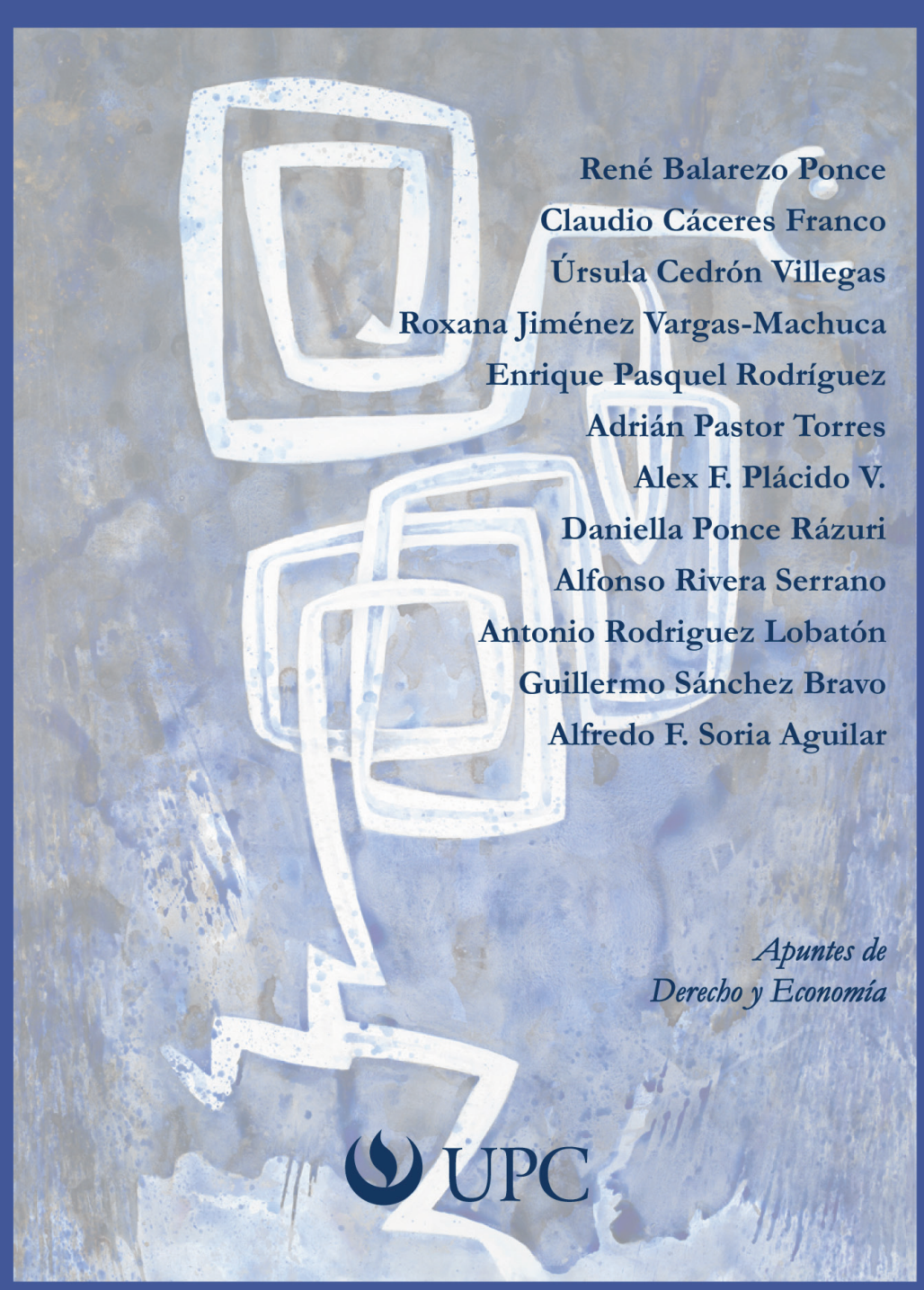




\section{El impacto de las}

\section{innovaciones tecnológicas en el Derecho Privado}

Alfredo F. Soria Aguilar (Compilador)

Apuntes de
Derecho y Economía 
El impacto de las innovaciones tecnológicas en el Derecho Privado

Compilador: Alfredo F. Soria Aguilar

Copyright (C) Universidad Peruana de Ciencias Aplicadas, 2009

Primera publicación: agosto de 2009

Impreso en el Perú - Printed in Peru

Cubierta:

Rhony Alhalel Lender

Corrección de estilo:

Jorge Coaguila

Diseño de cubierta:

Germán Ruiz Ch.

Diagramación:

Vanessa Heinicke

Editor Titular del Proyecto Editorial

(C) Universidad Peruana de Ciencias Aplicadas SAC.

Av. Alonso de Molina 1611, Santiago de Surco

Teléfono: 313-3333

www.upc.edu.pe

Tiraje: 500 ejemplares

Esta obra se terminó de imprimir en el mes de agosto de 2009, en los talleres gráficos de

Revistas Especializadas Peruanas SAC, ubicados en Emilio Althaus 355, Lince. Lima, Perú.

\section{Universidad Peruana de Ciencias Aplicadas (UPC) \\ Centro de Información}

Soria Aguilar, Alfredo F.

El impacto de las innovaciones tecnológicas en el Derecho Privado

Lima: Universidad Peruana de Ciencias Aplicadas (UPC), 2009

ISBN:

INNOVACIONES TECNOLÓGICAS Y DERECHO

PRIVADO, DERECHO A LA PROPIEDAD, CONTRATOS

INFORMÁTICOS, COMERCIO ELECTRÓNICO, FIRMA

ELECTRÓNICA, INTERNET, DERECHO DE FAMILIA Y

NUEVAS TECNOLOGÍAS

344.095 SORI

Registro de Proyecto Editorial:

Hecho el Depósito Legal en la Biblioteca Nacional del Perú No 2009-09512

Todos los derechos reservados. Esta publicación no puede ser reproducida, ni en todo ni en parte, ni registrada en o transmitida por un sistema de recuperación de información, en ninguna forma ni por ningún medio, sea mecánico, fotoquímico, electrónico, magnético, electroóptico, por fotocopia o cualquier otro, sin el permiso previo, por escrito, de la editorial.

El contenido de este libro es responsabilidad de los autores y no refleja necesariamente la opinión de los editores. 
Nutriente

Serie Germinal II: semillas del firmamento

Acrílico, tierra de color y tinta sobre papel templado sobre tela $1,42 \times 1,02 \mathrm{~m}$ 2006

La Universidad Peruana de Ciencias Aplicadas (UPC) agradece a Rhony Alhalel Lender la cesión de su cuadro reproducido en la cubierta. 


\section{ÍNDICE}

Presentación

Fernando Cantuarias Salaverry, Alfredo F. Soria Aguilar

PRÓlogo: un DERECHO DE CIENCIA FICCIÓN

Alfredo Bullard G.

CAPÍTULO 1

La contratación electrónica y el comercio electrónico

Roxana Jiménez Vargas-Machuca

CAPÍTULO 2

Alcances de la convención para la contratación electrónica transfronteriza y sus implicancias para el Perú

Guillermo Sánchez Bravo

CAPÍTULO 3

El contrato de bosting: apuntes acerca del contrato de alojamiento de un sitio en Internet

Alfredo F. Soria Aguilar

CAPÍTULO 4

La firma digital: incentivo al comercio electrónico

Claudio Cáceres Franco

Úrsula Cedrón Villegas 
La función de la responsabilidad objetiva o por riesgo en la creación de incentivos a la innovación tecnológica Alfonso Rivera Serrano

CAPÍTULO 6

Del alambre de púas al GPS.

La influencia de la tecnología en los derechos de propiedad

Enrique Pasquel Rodríguez

\section{CAPÍTULO 7}

¿Quién le pone el cascabel a Internet? Net Neutrality y la regulación del ciberespacio

Antonio Rodriguez Lobatón

CAPÍTULO 8

Hazas de suerte, panópticos y avatares, propiedad, intimidad y contratos en la Web 2.0

Antonio Rodriguez Lobatón

CAPÍTULO 9

La evidencia biológica y la "presunción de paternidad matrimonial»: el reconocimiento extramatrimonial del hijo de mujer casada

Alex F. Plácido V.

CAPÍTULO 10

Las innovaciones tecnológicas como elemento facilitador para incrementar el nivel de bancarización en el Perú

Adrián Pastor Torres

Daniella Ponce Rázuri 
CAPÍTULO 11

397

La evolución de los contratos inmobiliarios a partir de las nuevas tecnologías

René Balarezo Ponce

SOBRE LOS AUTORES

PUBLICACIONES 


\section{Presentación}

La idea de escribir este libro colectivo, que recopila exclusivamente artículos de profesores de la Facultad de Derecho de la Universidad Peruana de Ciencias Aplicadas (UPC), surgió como una propuesta dentro de las periódicas reuniones de trabajo que mantenemos los docentes del Área de Derecho Privado.

Fue precisamente en una de dichas reuniones, en la que todos los docentes del área conversamos sobre los diversos aspectos académicos y administrativos que nos permiten emprender coordinados planes de mejora en beneficio de la facultad y de nuestros estudiantes, donde surgió la idea respaldada de manera unánime por todos los docentes de reflexionar sobre la influencia y el impacto de las innovaciones tecnológicas en las distintas disciplinas del Derecho Privado.

Sin duda, el conocimiento humano progresa y evoluciona a una velocidad inimaginable. El ser humano, en su afán de perfección, crea, mejora, innova y busca nuevas formas de pensar y hacer las cosas. El Derecho, como ordenamiento normativo que rige la conducta humana en sociedad, no es ajeno a los cambios que introducen las nuevas tecnologías ni a los avances científicos. Por ello, el esfuerzo por entender la sociedad y pensar el Derecho desde la perspectiva de las nuevas realidades no puede ser ajeno al Derecho ni a aquellos que realizan la actividad docente. Plenamente conscientes de ello, pese a las grandes restricciones de tiempo que implican nuestras distintas actividades cotidianas, o en el ejercicio profesional del Derecho o como docentes universitarios, presentamos con gran satisfacción la materialización de un trabajo colectivo y coordinado, acerca de estos nuevos temas de mucha actualidad y relevancia.

El libro que presentamos, en esta oportunidad, cuenta con excelentes trabajos académicos elaborados en su integridad por profesores de nuestra Facultad de 
Derecho. Estos trabajos han sido agrupados considerando el impacto de las innovaciones tecnológicas en los distintos ámbitos del Derecho Privado. Así, entre los artículos sobre el impacto de las nuevas tecnologías en el Derecho de Contratos, contamos con los trabajos de Roxana Jiménez Vargas-Machuca, Guillermo Sánchez Bravo, Alfredo F. Soria Aguilar, Claudio Cáceres Franco y Úrsula Cedrón Villegas. En cuanto al ámbito de la responsabilidad civil, tenemos el aporte de Alfonso Rivera Serrano. Acerca del Derecho de Propiedad y del Derecho de Familia, respectivamente, contamos con los trabajos de Enrique Pasquel Rodríguez y Alex F. Plácido V. Los nuevos retos que plantea Internet al Derecho Privado son también debidamente analizados por Antonio Rodriguez Lobatón.

El impacto de las nuevas tecnologías incide también en distintos sectores específicos del ámbito privado. Por ello, el libro incluye el aporte de Adrián Pastor Torres y Daniella Ponce Rázuri, quienes analizan la incidencia de las nuevas tecnologías en el ámbito bancario, y de René Balarezo Ponce, que estudia la evolución de la contratación inmobiliaria como consecuencia de las innovaciones tecnológicas.

Como es evidente, dada la gran variedad, complejidad y novedad de los temas que plantean las innovaciones tecnológicas, de ningún modo pretendemos en esta publicación abordar ni agotar todos los temas o problemas del Derecho Privado vinculados a ellas. Por el contrario, este libro busca solamente ser un incentivo para quienes en el futuro quieran estudiar y pensar acerca de estos temas o de proponer otros nuevos vinculados a las nuevas tecnologías.

Si bien el entusiasmo y la dedicación de nuestros docentes fue importante para elaborar los diversos artículos que integran esta publicación, ello no hubiera bastado para hacer posible que usted pueda tener este libro en sus manos. La excelencia académica no se obtiene con el mero transcurso del tiempo o con frases publicitarias muy bien pensadas. La excelencia académica implica una clara actitud y decisión de todos los integrantes de una comunidad universitaria (autoridades, docentes, personal administrativo y estudiantes) de conseguir con gran esfuerzo y dedicación trascender las fronteras del conocimiento. Ello solamente se logra con la investigación.

La Universidad Peruana de Ciencias Aplicadas (UPC) precisamente ratifica ese compromiso en la búsqueda de la excelencia, respaldando este tipo 
de iniciativas académicas que nacen del esfuerzo de sus propios profesores e investigadores. Por ello, queremos agradecer sinceramente a la Universidad Peruana de Ciencias Aplicadas (UPC), a través de su Fondo Editorial, por haber editado esta publicación con el cuidado, profesionalismo y esmero que se convierte en un sello muy destacable en cada una de sus obras.

Lima, agosto de 2009

\section{Fernando Cantuarias Salaverry}

Decano de la Facultad de Derecho

Universidad Peruana de Ciencias Aplicadas (UPC)

\section{Alfredo F. Soria Aguilar}

Coordinador del Área de Derecho Privado

Universidad Peruana de Ciencias Aplicadas (UPC) 


\section{Prólogo}

En Blade Runner, de Ridley Scott, considerada por muchos la mejor película de ciencia ficción de todos los tiempos, un grupo de robots, creados para servir al hombre, se rebela y se convierte en una amenaza para los seres humanos. En Terminator, de James Cameron, y en toda su exitosa saga, una computadora (Skynet) toma el control del mundo y usa guerreros robóticos para asegurar que la humanidad quede sometida al reinado de la tecnología y las máquinas por ella creadas. En The Matrix, de los hermanos Wachowski, las computadoras han convertido a los seres humanos en «baterías» que sirven para suministrar energía, haciéndolos vivir en un sueño continuo creado por computadora, y que no es otra cosa que una realidad virtual y paralela, parecida a Second Life, solo que la vivimos sin haber consentido. En Metropolis, de Fritz Lang, una minoría controla a una mayoría alienada y pretende preservar la alienación creando un robot que reemplace a María, una líder mediática que podría construir puentes hacia la liberación. En la saga Star Wars, creada por George Lucas, un imperio dictatorial, conducido por un ser mitad hombre, mitad robot (Darth Vader) somete planetas enteros, basándose en una tecnología bélica jamás imaginada y tratando de aplastar a una especie de culto religioso sostenido por unos guerreros cuasi medievales denominados Jedis. En Alien, el octavo pasajero, de Ridley Scott, una empresa sin escrúpulos, usando un robot y una computadora, sacrifica a toda la tripulación de una nave dirigida a capturar a un indestructible monstruo espacial. En Minority Report, de Steven Spielberg, la tecnología, sumada al poder mental de unos médiums, permite capturar, condenar y encarcelar a supuestos 
delincuentes antes de que cometan un crimen, sin concederles derecho de defensa, prediciendo que van a cometer el delito.

La lista es larga y muestra la tendencia claramente dominante en el cine de ciencia ficción. En todas esas películas la tecnología aparece como algo malo, que se escapa del control de su creador (el ser humano) y es usada para explotar al hombre antes que para servirlo. Inevitablemente, la concepción del derecho como un ordenamiento justo cae aplastada frente a la dominación tecnológica y se convierte en una herramienta puesta al servicio del poder que esa tecnología concede a quienes la controlan. En más de una ocasión, quien controla la tecnología es la tecnología misma.

Los «buenos» en esas películas suelen ser quienes se rebelan contra el orden establecido, desafían el ordenamiento y las reglas imperantes, y pretenden derrocar a quien se ha establecido como autoridad en una legitimidad jurídica aparente. En la mayoría de esas películas, los héroes o heroínas se rebelan contra la ley y se comportan como outlaws que cuestionan la esencia del derecho existente, al que pretenden sustituir.

Las películas de ciencia ficción muestran la compleja relación entre derecho y tecnología. En la mayoría de ellas, el avance tecnológico va ligado a prepotencia, abuso, dictadura, arbitrariedad, falta de libertad. Se tiene la idea de que la tecnología crea poder y que ese poder se desbocará tarde o temprano, y convertirá el derecho en un instrumento del mal, que como tal debe ser combatido.

Pero el tema trasciende las películas. En sus orígenes, la imprenta de Gutenberg fue vista como un mecanismo tan alienante como lo son las computadoras e Internet para algunas personas: mecanismos que al masificar el conocimiento distraen al hombre de su quehacer diario, lo vuelven ocioso y apartado de la realidad. Antes se distraía leyendo libros y hoy googleando o entrando a Facebook. Ambas situaciones son vistas en sus tiempos como negativas por un buen grupo de gente.

Muchos se resisten (inútilmente) a los celulares o al blackberry que asumen como una pérdida de libertad. Otros consideran la televisión interactiva y los videojuegos como drogas destructoras de la juventud, y predicen que 
acabarán con la humanidad. Los avances en biotecnología son considerados deshumanizantes, cuando no pecaminosos, y de las críticas a las imágenes de mutantes monstruosos o de los X-Men, solo hay un paso.

El conflicto entonces se traslada al derecho. Se alzan voces dirigidas a reclamar más regulación para frenar los excesos de la tecnología, pues temen como en The Matrix o Terminator que esa tecnología tome el control y nos esclavice. Pero otros reclaman que el derecho legitime lo que la tecnología puede hacer, para permitir que el desarrollo continúe.

La vida, sin embargo, parece desmentir categóricamente a las películas y a las visiones pesimistas asociadas a la tecnología. Todo parece estar pasando de una manera muy distinta.

En los últimos 200 años la humanidad ha creado más riqueza y bienestar que en los anteriores 99.800 ańos. Los números lo demuestran. El ser humano moderno apareció hace solo unos 100.000 años. Durante 99.800 años permanecimos en un nivel de subsistencia con un crecimiento económico casi inexistente. En otras palabras, la productividad se mantuvo virtualmente constante. Las personas tuvieron un ingreso per cápita equivalente a como si hoy ganáramos, eliminado el efecto inflacionario, entre 400 y 600 dólares al año. Y con eso vivían nuestros antepasados.

Pero hace solo 200 años algo extraordinario pasó. La renta per cápita en Occidente comenzó a crecer a la «increíble» tasa de 0,75\% al año, para pasar a principios del siglo XX a 1,5\% y en los años 60 a 2,3\%. Y ese momento (hace 200 años) coincide con la aparición de la empresa moderna, la que hoy conocemos, la que es el mejor vehículo para canalizar la creatividad por los cauces adecuados y así generar impacto directo en las vidas de las personas. Ese salto empresarial se asocia al inicio de la revolución industrial, que no fue otra cosa que una gran revolución tecnológica.

Para que el lector tenga una idea de qué significa una cifra de crecimiento aparentemente tan insignificante, usemos un poco de matemáticas. Si alguien gana 50.000 dólares al año, en 25 años (solo una generación) a las tasas de crecimiento del producto bruto interno (PBI) indicadas, el ingreso per cápita real de sus hijos se habrá casi duplicado y en una generación más se habrá 
más que triplicado el de sus nietos. Si ganáramos 50.000 hoy, nuestros nietos ganarían cerca de 150.000 dólares al año. Y aunque no lo crea, en 400 años nuestros descendientes estarán ganando un millón de dólares diarios (mucho más que Bill Gates), con un nivel de vida acorde con ese ingreso el día de hoy. Sin embargo, gracias al pesimismo que uno ve en las películas de ciencia ficción, les aseguro que esos descendientes seguirán pensando que todo tiempo pasado fue mejor y que sus tatarabuelos vivían mejor.

En estos 200 años la expectativa de vida pasó de 30 años a más de 70. La mayoría de las personas no tenía hace un siglo agua corriente, desagüe, ni energía eléctrica, no podía ir a trabajar en auto y menos viajar por avión. Hace 100 años el ama de casa promedio se pasaba 12 horas diarias lavando ropa, cocinando, limpiando y planchando. Hoy le tomaría solo tres horas. En el camino inventos y tecnología traídos a nuestros hogares por creatividad y tecnología como lavadoras, aspiradoras, agua corriente, electricidad, calefacción, teléfonos, microondas y similares han reducido radicalmente nuestro tiempo de trabajo y han incrementado nuestro bienestar.

La productividad laboral se ha multiplicado cientos de veces. Solo imaginemos cuántos informes más puede un abogado elaborar en un mes gracias a que tiene un procesador de texto y puede acceder a información por Internet, y ello sin incluir el efecto de poder movilizarse en auto o en avión, de poder comunicarse por celular o de tener los correos electrónicos en su bolsillo gracias a su blackberry.

Todo ello ha tenido un impacto enorme en la reducción de la pobreza, pobreza que los enemigos del desarrollo sostienen ha aumentado en las últimas décadas, sin ningún número que los respalde. Usando los estándares que utilizamos hoy para medir la pobreza, hace un siglo el 90 por ciento de la población mundial eran pobres extremos. Hoy esa cifra se ha reducido a menos del 20 por ciento.

¿Cómo ha logrado eso el mundo occidental? Ningún país lo hizo con cambios bruscos y radicales. Ninguno logró crecer a tasas de 50 por ciento en un ańo. Los países exitosos han crecido de manera gradual, estable y continua, con tasas que parecen relativamente modestas y que rara vez pasan de un dígito al ańo. Nadie creció con saltos acrobáticos, sino acumulando pequeños y numerosos 
esfuerzos de crecimiento individual. El aparente pesimismo estructural, que parece siempre acompañarnos y hacernos pensar que cada vez estamos peor, es desmentido por las cifras y los datos. Nunca el mundo estuvo mejor que hoy y quizá nunca en la historia de la humanidad ha tenido un futuro tan promisorio.

¿Qué explica el cambio? Los economistas no han podido relacionar el crecimiento con la aparición de ninguna política estatal, al menos si definimos «política estatal» como planificación. No son los gobiernos los que nos hacen crecer. La única constante en las experiencias de éxito radica en liberar a las empresas para que sean ellas las que impulsen el crecimiento mediante creatividad e innovación. Y esa liberalización ha ido asociada al desarrollo de la tecnología. Cada punto del PBI está conformado por millones de actos creativos empresariales exitosos, de decisiones bien pensadas, bien ejecutadas, puestas al servicio del consumidor. Y en todos ellos la creación o el uso de tecnología ha constituido un componente esencial.

A los empresarios y a los emprendedores debemos agradecer estos milagros que facilitan nuestra vida todos los días: desde la medicina adecuada y oportuna hasta la comodidad de un viaje. Desde la comunicación por Internet hasta la televisión y el teléfono. Todo se lo debemos a estas organizaciones llamadas empresas, que ven las nuevas oportunidades y se arriesgan a explorar el camino para alcanzarlas, apuestan por nuevos conocimientos, los ponen en práctica y los convierten en tecnología.

Como dice Johan Norberg, si todo esto hubiera sido conseguido por los líderes políticos o políticas gubernamentales, lo consideraríamos uno de los más grandes logros de la humanidad en toda su historia. Pero como sus autores son millones de emprendedores o empresarios, la mayoría de las veces silenciosos y anónimos, caen en el olvido y vemos el efecto de la creatividad y la tecnología como algo tan natural como respirar, y no como una obra humana.

Si esto es cierto, ¿por qué las películas de ciencia ficción y el pensamiento popular suelen relacionar la tecnología con una visión pesimista del mundo, en el que el derecho ha sido puesto al servicio de poderosos explotadores para dominar a inocentes e ingenuos seres humanos que nos perdemos anónimamente en una "mayoría» sometida? 
Estudios psicológicos y económicos demuestran, por razones que no son fáciles de comprender, que los seres humanos somos pesimistas. Siempre decimos «todo tiempo pasado fue mejor», a pesar de que la experiencia práctica demuestra lo contrario. Nos encanta leer de profecías sobre el fin del mundo. No importa si es la Biblia, Nostradamus, los ambientalistas o el Fondo Monetario Internacional. Nunca ignoramos las predicciones de una calamidad, al punto que muchas mańanas nos hemos despertado aunque el mundo supuestamente debería haber desaparecido, constatando que la predicción estaba equivocada y que podremos seguir viviendo.

Y no es extraño asociar al pensamiento común esas calamidades, que llegan a pronosticar el fin de nuestros tiempos, con la tecnología. Para ejemplo las películas que citamos al inicio son una clara muestra de ello. En esas películas la tecnología ha acabado con la humanidad tal como la conocemos. Hace solo unas cuantas décadas todos estábamos sentados esperando que la guerra nuclear (una amenaza tecnológica) acabara con todos nosotros. Nunca ocurrió.

Hoy, con el fin de la Guerra Fría, hemos reemplazado misiles atómicos con una nueva amenaza derivada del desarrollo tecnológico: el calentamiento global que supuestamente convertirá al mundo en un infierno. En esos casos se asume que el derecho no solo es incapaz de evitarlo, sino que se ha vuelto cómplice de la calamidad, avalando, por ejemplo, la protección de la propiedad privada o la santidad de los contratos, o la protección de las inversiones, como mecanismos que permiten el uso presuntamente irresponsable de nuevas tecnologías, para que un grupo pequeño de privilegiados someta a las mayorías o las destruya. ¿Por qué existe ese paradójico pesimismo que se estrella con lo bueno que ocurre todos los días? ¿Por qué nos concentramos tanto en amenazas que nunca ocurren y olvidamos las bendiciones que recibimos todos los días?

El mejor ejemplo histórico de ese pesimismo inexplicable fue el del economista Thomas Malthus. Su pesimismo es quizá una de las principales razones de su fama. Profetizó en el siglo XIX que dado que la población crecía y se multiplicaba en progresión geométrica, mientras la capacidad de aumentar la producción de alimentos crecería en progresión aritmética, llegaríamos a la hambruna total y a la ruina de la humanidad porque las bocas que alimentar aumentaban más que la comida para alimentarlas. 
La predicción de Malthus, una de las más célebres por su supuesta base científica, nunca se cumplió.

Steven E. Landsburg comenta el error de Malthus. Cita a un tal Baxter (un hombre común y corriente) que decía que planeaba tener seis hijos para resolver el problema de la población mundial. Pero ¿por qué tener más hijos sería bueno para combatir la sobrepoblación? El razonamiento de Baxter era simple: la gente resuelve problemas y cuando más gente haya, más problemas se resuelven.

La pregunta es entonces ¿por qué un científico reputado como Malthus estaba en un error y por qué Baxter, un don nadie, estaba en lo correcto?

En realidad, es fácil descubrir el error de Malthus y tiene que hacer precisamente con no entender el rol de la tecnología. El razonamiento de Malthus no consideró que existía la creatividad. Ello lo condujo a tres errores.

El primero es que no entendió que la creatividad es un atributo que solo tienen los seres humanos. Ningún otro ser de la naturaleza posee la capacidad de crear algo nuevo. Ningún animal ha podido crear tecnología.

En un mundo con el doble de población, habrá el doble de posibilidades de tener genios, o el doble de posibilidades de tener personas creativas. Eso significa que habrá el doble de probabilidades de contar con nuevas ideas, $y$, por tanto, el doble de probabilidades de desarrollar tecnología nueva. Y buenas ideas nos resolverán problemas como, por ejemplo, producir más para alimentar más gente, comunicarnos mejor para difundir esas ideas y poder ponerlas en práctica, multiplicarlas y mejorarlas.

El segundo error en el cálculo de Malthus es que, en realidad, el doble de personas creativas no significa el doble de buenas ideas, sino muchas más. Malthus no solo olvidó la creatividad sino también a las empresas. Dos personas creativas pueden producir más del doble de ideas que una sola, simplemente porque la creatividad en equipo permite desarrollar ideas en progresión geométrica. La coordinación crea sinergias y ello aumenta la creatividad. Y las empresas exitosas son las que saben cómo juntar gente creativa para que coordinen entre ellas. Y luego, al contratar con otras empresas, o con los consumidores, la creatividad y la tecnología se reproducen sin límite. 
El tercer error está en olvidar que la creatividad no solo beneficia al creador o a la empresa que lo acoge. Como decía Thomas Jefferson, las ideas creativas son como encender una vela (hoy diríamos como encender un foco): una vez que lo haces no puedes evitar que la luz ilumine a los demás que están en la habitación.

Las ideas generan algo que los economistas llaman externalidades. Hay externalidades positivas que se dan cuando lo que trasladas es un beneficio. Una chica bonita que se arregla nos genera beneficios a quienes la miramos, y solo ella asume los costos.

El creativo es como una chica bonita: sus ideas nos benefician sin que él pueda evitar que lo hagamos. La idea se difunde y multiplica sus efectos sin límites, como la luz de la vela ilumina a todos en la habitación y no solo al que la encendió. Precisamente, por eso el símbolo de tener una idea es un foco de luz. Las empresas convierten «la vela» tecnológica en un poderoso reflector que ilumina a la humanidad entera con los beneficios de la creación.

Fueron entonces la tecnología y la creatividad empresarial las que dejaron en ridículo a Malthus.

En épocas en que nos hablan de crisis económicas o de efectos del calentamiento global que anuncian catástrofes muy similares a las que predijo Malthus, las profecías olvidan la capacidad de la tecnología y la creatividad de las empresas para superar los problemas.

En esa perspectiva, las relaciones entre el derecho y la tecnología aparecen como mucho más amigables y productivas para el bienestar de todos de lo que solemos creer y, por supuesto, de lo que se ve en las películas de ciencia ficción.

El impulso de la creatividad que genera la tecnología proviene, en principio, de una serie de definiciones legales mínimas que se pueden constatar en los países que se han desarrollado y que son a su vez los que producen más avances tecnológicos. En primer lugar, una mejor definición de los derechos de propiedad que permiten que los empresarios y los ciudadanos comunes puedan soportar los costos de sus acciones y recibir los beneficios de su esfuerzo. Al definirse mejor la propiedad y marcarse una mayor circulación de la riqueza y su despersonalización (a través de inversiones en acciones), se reúnen grandes cantidades de capital para hacer las inversiones que exige la innovación tecnológica moderna. 
Por otro lado, la reducción de costos de transacción gracias a una mejor definición legal sobre el cumplimiento de los acuerdos, y, en particular, la aparición de mecanismos judiciales o arbitrales efectivos de ejecución de obligaciones permitieron intercambios más efectivos y masificados, que impulsaron el desarrollo de tecnologías para satisfacer nuevas demandas.

En tercer lugar, el mejor funcionamiento de reglas de responsabilidad extracontractual perfiló una mejor internalización de las externalidades, que derivaron en productos y servicios cada vez más seguros a menos costo.

Pero la relación entre derecho y tecnología es de dos vías, y generó un círculo virtuoso que ayudó a su vez a un mayor desarrollo. La tecnología permitió una mejor definición de derechos de propiedad, gracias a sistemas que permiten una mejor identificación de violaciones y una mejor definición y enforcement de los derechos. Por otra parte, en el mundo de los contratos, los costos de transacción se han reducido en ciertas transacciones a niveles cercanos a 0 , gracias a Internet y a la contratación electrónica. Hoy se puede comprar un libro a miles de kilómetros de distancia solo haciendo un clic con el dedo en el mouse. Y, además, los sistemas de internalización de externalidades han encontrado en la tecnología soluciones antes inimaginables para identificar responsables y hacerles pagar por los costos que generan a terceros.

Lo cierto es que las películas de ciencia ficción han demostrado ser eso mismo: películas de ficción. La realidad nos muestra a la tecnología más como un aliado de la libertad, del desarrollo, y como un mecanismo que aporta a un derecho más justo y eficiente. Lejos de lo que aparece en las pantallas del cine, una predicción basada en la experiencia nos mostraría posiblemente mundos mucho mejores, con mayor bienestar y con mejores posibilidades de realización para todas las personas. El derecho sería también más eficaz, moderno y capaz de lograr la convivencia entre las personas.

Los trabajos que componen este volumen son una demostración de ello. No parecen películas de ciencia ficción, sino todo lo contrario. Nos muestra una visión más optimista del futuro. Todos los trabajos tienen en común analizar la relación entre el derecho y la tecnología y facilitan apreciar la contribución de esta relación como una que refuerza la libertad y aumenta el bienestar. 
En lo que se refiere a la propiedad, el excelente y entretenido artículo de Enrique Pasquel «Del alambre de púas al GPS. La influencia de la tecnología en los derechos de propiedad» nos muestra, con ejemplos concretos, cómo la tecnología ha ido reduciendo los costos de crear derechos de exclusión, lo que permite hoy pensar en propiedad sobre ballenas, animales silvestres, calles, agua, atmósfera, y otros bienes. Ello era algo que hace unos siglos considerábamos impensable. Sistemas electrónicos o de rastreo satelital pueden permitir que privaticemos las calles cobrando a los usuarios a fin de mes por las calles por las que circularon sus automóviles. Ello solo es posible con la tecnología moderna. Se puede usar tecnología para rastrear una ballena y convertirse en su propietario. Sus ejemplos nos muestran que la propiedad se crea estableciendo una relación entre el costo marginal frente al beneficio marginal. La tecnología, al bajar los costos de enforcement de la propiedad, abre la puerta para usar ese derecho para crear incentivos que eviten la contaminación ambiental o la extinción de los animales. ¿Por qué no avanzamos lo que se podría en ese camino? Porque la decisión política va detrás de la tecnología. Sin embargo, a pesar de ello, seguimos avanzando.

En el mundo de los contratos, los efectos de esta ciencia ficción jurídica no son menos llamativos. En el detallado y concienzudo trabajo de Roxana Jiménez «La contratación electrónica y el comercio electrónico» se analiza con cuidado y detenimiento estas nuevas formas de contratación, en que la voluntad se ha recreado como un nuevo concepto. Podemos ahora hablar de «voluntad virtual». ¿Puede la concepción civilista de contratos ser útil para entender el problema? ¿O debemos liberarnos de esa concepción para que la contratación electrónica pueda bajar los costos de transacción a casi 0 y multiplicar exponencialmente el número de transacciones y con ello el bienestar?

En la misma línea, el trabajo de Claudio Cáceres y Úrsula Cedrón sobre «La firma digital: incentivo al comercio electrónico» nos conduce a una perplejidad similar a la que debió haberse enfrentado el primer hombre al que le dijeron que su firma con una pluma y tinta podía obligarlo. El problema generado por esa "nueva tecnología» debe haber sido muy similar al que nos plantea la firma digital, herramienta sin la cual la seguridad en las transacciones se perdería. El 
trabajo recoge y analiza con precisión y detalle los alcances legales de esta figura y sobre todo qué ajustes son necesarios para seguir avanzando.

En el trabajo de Guillermo Sánchez, titulado «Alcances de la convención para la contratación electrónica transfronterizas y sus implicancias para el Perú», el autor nos muestra, con conocimiento de causa y dando a la vez una voz de alarma sobre la situación en el Perú, cómo el avance tecnológico ha ido desdibujando el concepto de frontera, con base en el cual el Estado ejerce soberanamente su facultad reguladora, porque las transacciones ya no tienen -como se ha asumido siempre- lugar de celebración. La convención de la CNUDMI (Uncitral) para el comercio electrónico es justo una herramienta creada para hacer viable su funcionamiento, sin perder la seguridad jurídica que estas transacciones deben tener.

Por su parte, Alfredo Soria aborda el tema desde otra óptica. En su trabajo, "Apuntes acerca del contrato de hosting de un sitio en Internet», analiza no cómo estas nuevas tecnologías impactan en los contratos, sino cómo pueden los contratos ayudar a consolidar estas tecnologías, y para ello analiza cómo opera y cómo debería regularse el contrato de hosting. Con un estricto y cuidadoso análisis jurídico nos explica los elementos del tipo contractual, cuáles deben ser los elementos que se deben considerar en su celebración y qué problemas debe el derecho resolver.

En la misma línea hay que destacar dos trabajos de Antonio Rodríguez Lobatón ( Net neutrality y la regulación del ciberespacio. ¿Quién le pone el cascabel a Internet?» y "Hazas de suerte, panópticos y avatares, propiedad, intimidad y contratos»). Con un amplio conocimiento del tema y con un manejo de fuentes y ejemplos envidiable, el autor nos invita a una profunda reflexión, muy bien documentada, sobre los retos que Internet plantea al Derecho Privado. Un sistema que se basa en una concepción tan distinta del intercambio de información, podría derivar en mecanismos de discriminación o trato diferencial en el que unos puedan sacar provecho de los otros. Ello plantea problemas de muy difícil solución. De la misma manera, como ha sido un reto desde épocas decimonónicas, evitar que los flujos de mercancías puedan verse afectados por prácticas públicas o privadas que las distorsionen, lo mismo 
puede ocurrir con los flujos de información. Y surge la eterna paradoja en que intervenir para que haya libertad nos hace menos libres. ¿Debe o no acogerse el principio de net neutrality para evitar distorsiones o es su adopción lo que generará las distorsiones? Y, por otra parte, ¿cuál es el tratamiento que debemos dar a los bienes y derechos que se están creando en los mundos virtuales? ¿Son los bienes adquiridos o creados en Second Life de titularidad de los usuarios o no? ¿Su sustracción puede ser sancionada como robo? ¿Cuáles son los límites a la protección de la intimidad en sistemas como Facebook? ¿Puede el derecho darnos soluciones a estas preguntas? Y de ser así, ¿qué derecho? ¿El estatal o el privado creado por generación espontánea de la interacción entre internautas?

Además, se abordan en este libro temas particulares vinculados a mercados específicos, cuyo impacto, en especial en lo contractual, no se puede dejar de lado. En el trabajo de Adrián Pastor y Daniella Ponce «Las innovaciones tecnológicas como elemento facilitador para incrementar el nivel de bancarización en el Perú» se analiza, con información muy bien recopilada y analizada, el aporte que la tecnología, en especial la informática, puede tener en elevar los niveles de bancarización de las operaciones. Finalmente, bancarizar no es otra cosa que buscar reducir los costos de transacción mediante el uso de intermediación financiera y de negocios, usando bancos o entidades financieras. Al contribuir la tecnología a reducir los costos de transacción de usar bancos, se contribuye a su vez a disminuir los costos de transacción en toda la economía.

Por su parte, René Balarezo nos muestra cuál es «la contribución de las nuevas tecnologías en el desarrollo de la contratación inmobiliaria». Para ello nos ilustra cómo una serie de herramientas tecnológicas, que van desde aplicaciones informáticas a Registros Públicos (que ha sustituido, por ejemplo, el acceso de información por medio de lecturas de tomos humedecidos en los sótanos del Palacio de Justicia por un conveniente acceso mediante Internet a las fichas registrales desde tu propia computadora personal) hasta google earth, que supera en precisión a cualquier catastro, han reducido sustancialmente los costos de transacción en los mercados inmobiliarios, ofreciendo mayor seguridad y rapidez a menor costo.

Álex Plácido, en su trabajo «La evidencia biológica y la presunción de paternidad matrimonial: el reconocimiento extramatrimonial del hijo de 
la mujer casada», nos muestra cómo los avances tecnológicos comienzan a retar principios comúnmente aceptados, como la presunción de paternidad matrimonial. Así, ni el carácter usualmente tradicional que se da al Derecho de Familia lo salva de los impactos de la tecnología.

Finalmente, Alfonso Rivera, en su trabajo «La función de la responsabilidad objetiva por riesgo en la creación de incentivos a la innovación tecnológica», nos muestra sesudamente por qué los sistemas de responsabilidad no solo se diseñan y cumplen su rol, desincentivando externalidades negativas y haciendo pagar a los innovadores o a las empresas los costos de los daños que causan sus innovaciones, sino que puede ser usado también para fomentar las externalidades positivas que, como la vela, iluminarían a todos. Por ello, la responsabilidad no se vincula solo con evitar daños, sino también con generar beneficios y motivar que sigamos innovando.

En síntesis, este libro nos confirma que la tecnología es, antes que nada, una buena noticia, y que su sociedad con el derecho está lejos de ser contraria a los intereses de la humanidad. La tecnología da poder, y el derecho administra poder y le debe poner límites. Sin embargo, el principio más evidente es que la tecnología, al reducir los costos de hacer muchas cosas, democratiza el poder, y lo distribuye entre varios que hoy pueden hacer lo que antes no podían.

La tecnología nos da empowerment a los ciudadanos. Hoy, la televisión satelital o Internet hacen imposible a las dictaduras mentir sobre lo que pasa en el resto del mundo. Un teléfono celular, al alcance de personas de incluso modestos ingresos, nos permite estar comunicados con el resto del mundo, algo reservado antes a un grupo de privilegiados. Los avances médicos han elevado las expectativas de vida multiplicándolas en 2.5 veces en solo 100 años, en beneficio de todos, ricos y pobres. Hoy por skype se puede hablar gratis con el otro lado del mundo, con una llamada que hace 10 años costaba más de doscientos dólares. Internet nos da acceso a información no contenida en ninguna biblioteca del mundo, a la que accedemos con un mouse en la mano. Hoy millones de personas vuelan de un país a otro con costos accesibles, lo que antes estuvo reservado a unos cuantos privilegiados, que tenían que conformarse con ir en barco. La tecnología distribuye el poder antes de concentrarlo, justamente a contramano a como suelen sugerir las películas de ciencia ficción. 
Este libro nos muestra que la ciencia ficción no tiene por qué ser pesimista. Demuestra que la tecnología aporta a democratizar el poder, y al hacerlo le da oportunidades al derecho de ser más democrático y justo, de permitir un mayor juego a la libertad y a la capacidad del hombre de interrelacionarse.

Por ello, si está en una librería leyendo este prólogo para ver si decide comprar este libro, le recomiendo que lo haga. Dedique algunas horas a leerlo y deje sobre el estante el DVD con la película de ciencia ficción que pensaba ver. Le aseguro que no solo aprovechará mejor su tiempo, sino que además tendrá una versión más realista del futuro.

Alfredo Bullard G. 
Capítulo 1

\section{LA CONTRATACIÓN ELECTRÓNICA Y EL COMERCIO ELECTRÓNICO}

Roxana Jiménez Vargas-Machuca*

* Profesora de la Facultad de Derecho en la Universidad Peruana de Ciencias Aplicadas (UPC). 


\section{INTRODUCCIÓN}

\section{El contexto actual y la problemática relativa a la contratación electrónica}

Los tiempos actuales, marcados de modo indiscutible por la globalización y la tecnología, nos sitúan en un contexto distinto al de hace unas pocas décadas. La velocidad es la nota característica de la época en que vivimos, caracterizada por la vertiginosidad para traspasar etapas, toda vez que en el pasado estas se modificaban después de profundos cambios dados en un prolongado lapso de tiempo.

Nuestra época o era ha sido denominada de diversas formas: posindustrial, tecnológica, informatizada, de la aldea global, de la tercera ola, posmoderna, poscapitalista, entre otros diversos términos cuyo concepto trasunta una evolución de orden tecnológico. Su característica es la rapidez en las comunicaciones, en las transacciones, en la paradójica conversión del individualismo a la masificación de las personas ${ }^{1}$.

La velocidad del desarrollo tecnológico es creciente, antela comparativamente más lenta capacidad de respuesta del derecho, lo que hace difícil abarcarlo e inclusive comprenderlo en todas sus implicancias. Empero, es necesario incluirlo como parte de un todo en continuo movimiento, por cuanto una de las características de la tecnología es su capacidad de inserción en la vida social

\footnotetext{
${ }^{1}$ Decimos paradójica, pues tal masificación ha sido producto del propio individualismo, del cual hoy puede hablarse como postura personal y egoísta -en términos hobbesianos- de cada uno; pero en cuanto al movimiento de la sociedad, en lo concerniente al tráfico de bienes y servicios, en términos sociales y económicos, es claro que ya no es preponderante el individuo sino el conglomerado de individuos sin rostro, anónimos, masificados, que realizan transacciones diarias (cfr. Jiménez Vargas-Machuca 2000).
} 
en las maneras más insospechadas, debido a que la tecnología es el empleo «del conocimiento científico para especificar las formas de hacer cosas de una manera reproducible» ${ }^{2}$.

Por otro lado, ante estas realidades de la innovación científica y su repercusión en los modos de intercambio en la sociedad, se encuentra la multiculturalidad ${ }^{3}$. Una de las funciones del derecho consiste en ser el canal que permita lograr las metas que la sociedad desea obtener; de ahí la necesidad de su correlación con esta; de lo contrario, el propio derecho será el que obstaculice el desarrollo social ${ }^{4}$. La validez social de la norma es proporcionada por el reconocimiento de los destinatarios como válida o justificatoria, lo que le agrega un importante aspecto motivacional. Se da cuando los miembros de un grupo pueden legítimamente esperar unos de otros que cada uno de ellos oriente su acción por los valores fijados por la norma ${ }^{5}$, dándose una armonía entre el derecho y la sociedad, y no un divorcio entre ambos ${ }^{6}$.

En tal sentido, todo operador jurídico debe tener presente la necesaria correlación entre el ordenamiento social (sociedad) y el ordenamiento jurídico (derecho) como categorías que integran un solo ordenamiento construido y reconstruido cotidianamente en función del desarrollo de las necesidades

\footnotetext{
${ }^{2}$ Definición de Harvey Brooks, citada en Ortiz Caballero 1996: 60.

${ }^{3}$ Sobre la multiculturalidad, Fernando de Trazegnies opina que «muchos de los países latinoamericanos de hoy son extraordinariamente complejos: tienen efectivamente una realidad multicultural, en la medida en que todas esas raíces culturales no se han logrado integrar totalmente y los diferentes grupos muestran todavía características propias» (cfr. De Trazegnies Granda 1994: 66-67).

${ }^{4}$ Por ello, la legalidad necesariamente debe estar acompañada por la legitimidad, la cual es proporcionada por la vigencia o validez social de las normas legales (cfr. Habermas 1990: 127-129).

${ }^{5} \mathrm{La}$ «doble vida» jurídica aparece cuando las normas carecen de este reconocimiento social, es decir, cuando los agentes internamente no consideran que merecen su acatamiento. Las razones pueden ser múltiples: podría tratarse de una norma injusta, o desfasada de la realidad actual, etcétera; en suma, se trataría de un divorcio del derecho con la realidad.

${ }^{6}$ Este fenómeno no es extraño, particularmente en los países que, como el nuestro, se encuentran regidos por sistemas jurídicos pertenecientes a la tradición romano-germánica (civilistas), y por ello los agentes sociales y económicos siempre han sentido un cierto recelo del derecho, pues, como muy gráficamente describe Eduardo Benavides Torres, «A menudo tenemos una visión del derecho demasiado ascéptica y estilizada. Pensamos en el derecho como una entelequia aislada, lejana y distante, a la cual metemos en una campana de cristal (para que no se contamine con el polvo de lo cotidiano). A menudo, esto significa dejar que la realidad económica y social se eche a correr mientras el derecho, arrastrando la armadura de la prudencia, camina a paso lento» (cfr. Benavides Torres 1997: 179).
} 
socialmente útiles. Por su parte, el derecho tiene una capacidad coercitiva que lo convierte en un útil instrumento de ordenación, pero este orden que impone no se limita a ser impositivo o represivo ${ }^{7}$, pues también facilita y abre el camino para otras conductas. Posee, así, una riqueza estratégica, siendo la ley la cristalización -siempre incompleta y con vocación de replanteamientodel conflicto de intereses y valores que se produce dentro de un cierto espacio cultural y de acuerdo con determinadas reglas de juego ${ }^{8}$.

Por ello, el mundo humano no debe ser entendido mecanicistamente como una estructura predeterminada, donde cada hombre, cada contacto, cada cosa tiene su lugar. Es más bien un mundo haciéndose y deshaciéndose bajo los impulsos anárquicos de la libertad y bajo la vocación intrínseca por el orden ${ }^{9}$. En el derecho esa dialéctica se manifiesta en las polaridades de interés público e interés privado, derechos del individuo y derechos del Estado, normas imperativas y libertad contractual, justicia y seguridad jurídica.

En suma, el derecho y la sociedad deben alimentarse mutuamente a fin de no convertirse en dos categorías autónomas y alejadas; el derecho debe aggiornarse continuamente, pues si se ignora la aplicación práctica de las materias sobre las que se estudia o legisla, estamos ante un hermoso reloj que no está hecho para que marche ${ }^{10}$, con lo cual se pierde el sentido y se obstruye el decurso del sistema jurídico.

Actualmente nos encontramos en una etapa de inmersión en una cultura basada en la automatización de la información, con el avance a ritmo acelerado y creciente de las tecnologías telemáticas y la microelectrónica, lo que se traduce en formas de relacionarse y de efectuar transacciones a todo nivel, sobre bienes y servicios principalmente, comprendiendo la realización de diversos actos cotidianos, almacenar información cuantiosa, e importando formas novedosas de trabajar, estudiar, jugar, pagar, negociar, contratar, vincularse socialmente, entre otros.

\footnotetext{
${ }^{7}$ Cfr. De Trazegnies Granda 1994: 748 y ss.

${ }^{8}$ El orden no cancela la libertad; por el contrario, esta pone en conflicto todo el tiempo al orden jurídico, por lo que este siempre lucha por someterla. Es lo que se denomina la dialéctica productiva del orden y el desorden, esto es, concebir la manera de vivir en común a pesar de la libertad, y sin sacrificarla.

${ }^{9}$ Cfr. De Trazegnies Granda 1994: 748 y ss.

${ }^{10}$ Cfr. Ihering 1933: 13.
} 
En términos de comunicaciones e información, la innovación tecnológica más importante de las últimas décadas del siglo XX ha sido -y sigue siendo hoy, a fines de la primera década del siglo XXI- la red de redes: Internet (International Network of Computers). Por ello, el «notable y significativo desarrollo alcanzado por la red Internet en la década de 1990 ha propiciado la entrada en escena de un nuevo tipo de contratación electrónica, un fenómeno que está marcando nuevos paradigmas tanto en el plano económico como en el jurídico» ${ }^{11}$. En efecto, hacia fines de la década de 1990 Internet ya se consideraba un fenómeno tecnológico estelar, un paso decisivo en el avance de los sistemas de información y comunicación ${ }^{12}$. La importancia de esta tecnología es tal que ha sido comparada con la invención de la imprenta por Gutenberg ${ }^{13}$.

Estos nuevos paradigmas exigen, pues, un replanteamiento jurídico de la contratación acorde con semejante evolución. Las relaciones comerciales que se entablan por cualquier tipo de personas mediante soportes electrónicos se denomina comercio electrónico o e-commerce $e^{14}$, comprendiendo principalmente

\footnotetext{
${ }^{11}$ Cfr. Guisado Moreno 2004.

${ }^{12}$ Cfr. Pérez-Luño 1998.

${ }_{13}$ «Internet tiene sus inicios en Estados Unidos durante los años setenta, cuando se llevó a cabo el proyecto militar denominado Advanced Research Projects Agency (ARPANet). Este sistema permitía la conexión de terminales o computadoras similares y fue diseñado para sobrevivir a un ataque nuclear. En los años ochenta, la agencia federal estadounidense National Science Foundation (NSF) empezó a expandir su red utilizando la tecnología de ARPANet, con el objeto de conectar varias universidades y luego para enviar mensajes electrónicos. Recién en la década de los noventa, y como consecuencia del enorme desarrollo de la industria de la computación en hardware y software, se hace posible el desarrollo de Internet como medio para comunicarse y, posteriormente, para realizar publicidad y hacer negocios a través de una computadora conectada directamente a la red de redes, mediante un módem con línea telefónica y un software de navegación.

El 6 de diciembre de 2000, el presidente del Organismo Supervisor de Inversión Privada en Telecomunicaciones (Osiptel), Jorge Kunigami, se presentó ante la Comisión de Ciencia y Tecnología del Congreso de la República del Perú para manifestar que el Estado debía tener un rol proactivo en el desarrollo de Internet y las tecnologías de la información en el país. Precisó que se debía promover el desarrollo de medios de acceso (teléfonos fijo o móvil, tenencia de computadoras o televisión por cable), contar con diversas alternativas tarifarias (a través de la introducción de nuevas tecnologías, planes tarifarios, tarifa plana), implementar un programa de educación y capacitación en esta materia, emitir y adecuar el marco regulatorio e impulsar el uso de estas tecnologías en las instituciones públicas. También manifestó que el número de usuarios de Internet se ha triplicado desde 1998 y que en el 2000 se contaba con más de 800 mil personas que accedían a Internet a través de cabinas públicas y centros laborales (vía líneas dedicadas) o desde sus domicilios (acceso conmutado)» (cfr. Soto Coaguila 2002).

${ }^{14}$ Cfr. Torres Álvarez 2005: 48.
} 
la red de redes -Internet- o, definido de modo más amplio, como el conjunto de transacciones comerciales y financieras realizadas por medios electrónicos, que incluye texto, sonido e imagen ${ }^{15}$. Se trata de un sistema global que, por medio de la utilización de redes informáticas -en particular Internet-, permite crear un mercado electrónico de todo tipo de productos, servicios, tecnologías y bienes que incluye todas las operaciones necesarias para concretar operaciones de compra y venta, matching, negociación, información de referencia comercial, intercambio de documentos, acceso a la información de servicios de apoyo (aranceles, seguros, transportes, etcétera) y banking de apoyo; todo ello en condiciones de seguridad y confidencialidad razonables ${ }^{16}$.

Así, como sabemos, a fin de que las personas puedan realizar tales intercambios -como la compra de prendas de vestir, libros, automóviles, alimentos, materia prima, etcétera- no solo de modo lícito, sino eficiente, se va a requerir que estos negocios se encuentren inmersos y regulados por el derecho patrimonial, el cual reconoce la importancia del intercambio de bienes y servicios en la sociedad, y proporciona reglas que permitan que este se desarrolle asignando de manera óptima los recursos, pues cuando una relación de intercambio o de cooperación adquiere juridicidad ello significa que las partes pueden exigirse el cumplimiento de lo pactado, pudiendo acudir en general a las formas de solución de controversias y, en particular, al medio de solución de conflictos por excelencia: el sistema judicial.

Es así como el Estado proporciona credibilidad al contrato, por cuanto la finalidad del derecho de obligaciones es asegurar que se realicen los intercambios de manera eficiente, teniendo por función proporcionar un conjunto de reglas y de mecanismos para ello, por medio de la reducción de costos de transacción

\footnotetext{
15. El «comercio electrónico» es mucho más que vender y comprar productos vía Internet; es un cambio en la forma de personalizar, distribuir e intercambiar productos, que les permite a las empresas ampliar la cuota de mercado frente a la competencia. Asimismo, las herramientas actuales posibilitan gestionar la cadena de abastecimiento de punta a punta, desde los fabricantes y proveedores hasta los vendedores minoristas, con la opción de automatizar todo el proceso administrativo-contable del negocio (cfr. Debattista 2005).

16. Cfr. Piaggi 2001: 69.
} 
(mediante normas supletorias y reduciendo complejidades y complicaciones innecesarias) y asegurando el cumplimiento de las relaciones obligatorias. Entonces, el instrumento legal regulado por el ordenamiento jurídico que los vincule jurídicamente a efecto de que, en caso de incumplimiento de una parte contratante, la otra pueda solicitar su ejecución, la resolución de la relación obligatoria y/o la indemnización por los daños sufridos, es el contrato.

Como señala Rico: «Actualmente la mayoría de las legislaciones admite la validez y eficacia de la contratación realizada a través de medios electrónicos; este reconocimiento tiene lugar a partir de la Ley Modelo de la Comisión de las Naciones Unidas para el Derecho Mercantil Internacional sobre Comercio Electrónico, en cuyo artículo 11 se regula la validez y formación de los contratos electrónicos al establecer 'en la formación del contrato, de no convenir las partes otra cosa, la oferta y su aceptación podrán ser expresadas por medio de un mensaje de datos. No se negará validez o fuerza obligatoria a un contrato por la sola razón de haberse utilizado en su formación un mensaje de datos' ${ }^{17}$.

En el escenario descrito, resulta pertinente preguntarse si en nuestro ordenamiento jurídico el contrato celebrado por medios electrónicos se encuentra amparado por las reglas del Código Civil ${ }^{18}$, a fin de establecer si esta

\footnotetext{
17. Cfr. Rico Carrillo 2004.

18. El artículo 1351 del Código Civil define el contrato como el acuerdo de voluntades de dos o más partes destinado a crear, regular, modificar o extinguir relaciones jurídicas patrimoniales.

19. «El comercio electrónico no se limita a aquellos productos que se pagan con tarjeta de crédito y se envían al consumidor por correo. Los conceptos de venta y prestación de servicios cada día se asocian más. Por ello, está ganando más espacio en Internet la comercialización de bienes de alto valor, como automóviles o inmuebles. Aunque el cierre de la compra de dichos productos no se da en la red, el cliente inicia la negociación en la web, principalmente para hacer el estudio de mercado. Fiat fue la primera automotriz que ofreció un servicio de esta índole en Brasil. En 1996 lanzó el Fiat Online, un site en el que el consumidor puede armar el coche que desea, eligiendo desde el color hasta los accesorios. Al seleccionar las características del auto, el precio se actualiza automáticamente. Generalmente, tras armar su auto por Internet, el consumidor va a una concesionaria para formalizar su pedido. El plazo promedio de entrega es de seis semanas. Actualmente, otras automotrices, como General Motors y Ford, ofrecen servicios similares en Brasil. Según Carlos Murillo Moreno, gerente de Publicidad de Fiat, la empresa no sabe exactamente cuál es el porcentaje de ventas iniciadas en la web. Es difícil saberlo con precisión porque la persona no necesita registrarse para hacer su consulta en Fiat Online. Lo que podemos decir es que el site recibe unas 100 mil visitas al mes, mientras que las ventas mensuales de vehículos de Fiat suman cerca de 30 mil unidades»... Según (Mario Murillo), hasta ahora Fiat ha invertido en el site aproximadamente 330
} 
nueva forma de contratar altera las estructuras del derecho contractual vigente, dado que, habiendo eliminado fronteras, la contratación ya no es nacional sino mundial, virtual y globalizada ${ }^{19}$. Es por ello primordial incidir en la importancia de la contratación electrónica o telemática de modo coherente e integral, «tratando temas como los supuestos de contratación electrónica, el principio de equivalencia funcional y la manifestación de voluntad electrónica, la oferta, la aceptación, y otras declaraciones en la contratación electrónica [...] tanto en el ámbito privado como en el público ${ }^{20}$.

\section{LOS CONTRATOS INFORMÁTICOS}

Los contratos informáticos son aquellos que tienen por objeto bienes o servicios informáticos, entre los que se encuentran el software, el hardware, datos informáticos, servicios informáticos.

En este punto, a fin de analizar el concepto señalado, es menester recordar lo relativo al objeto del contrato de acuerdo con nuestro ordenamiento jurídico. $\mathrm{Al}$ respecto, en términos muy generales, las posiciones que han venido evolucionando sobre el objeto del contrato son las siguientes: 1) es la prestación o prestaciones que emanan del contrato (conducta consistente en dar, hacer o no hacer); 2) es el bien o servicio materia del mismo (en una compraventa podrá ser el automóvil, el inmueble, el cuadro, el libro; en la prestación de servicios sería la confección del informe jurídico del abogado patrocinante, la redacción de la biografía, etcétera); 3) es la relación jurídica obligatoria u obligacional.

El Código Civil peruano acoge la última tesis, al establecer (artículo 1402)

mil dólares. «En breve será posible que el cliente haga su pedido vía Internet», dice. No obstante, recalca que la compra del vehículo aún dependerá de que el cliente la confirme personalmente en la concesionaria. «Un automóvil es un bien caro. No podemos correr el riesgo de permitir que un adolescente, por ejemplo, utilice los datos del padre y bromeando compre un automóvil», afirma el gerente de publicidad de Fiat. La idea del site surgió en la unidad de Fiat de Brasil, pero hoy existen versiones para los principales países de Europa, donde la automotriz italiana está presente, así como para Argentina y Venezuela. Además, toda la red de concesionarios de Brasil usa el sistema de intranet para efectuar los pedidos de los modelos que desea recibir. «Prácticamente todas las solicitudes se hacen a través de nuestra red interna, indicó» (cfr. Cáceres 2005: www.cosapisoft.com.pe/andromeda/e_commerce.htm, citado en Soto Coaguila 2005: 151).

20. Cfr. Núñez Ponce 2008: 36. 
que el objeto del contrato consiste en crear, regular, modificar o extinguir obligaciones. Así, el contrato crea una relación jurídica obligacional entre las partes contratantes, en virtud del cual el deudor está obligado a ejecutar una prestación en favor del acreedor, quien por su parte tiene la facultad de exigirla. Esta relación jurídica obligatoria creada por el contrato tiene por objeto la prestación (comportamiento o conducta del deudor destinada a cumplir su obligación). La prestación puede consistir en una conducta de dar, de hacer o de no hacer, tendente a satisfacer el interés del acreedor, cuyo objeto, a su vez, consiste en los bienes o servicios materia del negocio.

Ahora bien, como he señalado al inicio de este punto, la doctrina ha definido a los contratos informáticos como una categoría contractual autónoma; esto es, como un contrato atípico que requiere una regulación legal específica.

En esa línea de pensamiento, se ha dicho que los contratos informáticos son aquellos cuyo objeto viene constituido por un bien (cosa) y/o por un servicio informático ${ }^{21}$; que tienen por objeto los bienes y/o servicios relacionados con la informática ${ }^{22}$, que su objeto recae sobre bienes como el ordenador, el sistema de telecomunicación o la creación, confección y desarrollo de programas, y de servicios como el uso de equipos, la explotación de programas, la consulta a base de datos o archivos, el mantenimiento, la auditoría y la financiación ${ }^{23}$; que son «una expresión que la doctrina denomina tanto a los contratos referidos a bienes y servicios informáticos como a los contratos celebrados entre computadoras» ${ }^{24}$; que su fin consiste en la prestación de bienes y servicios vinculados a la información automatizada ${ }^{25}$; que constituyen «los procesos negociales que tienen por objeto la prestación de bienes y servicios vinculados a la información

21. Cfr. Gete-Alonso Calera, María del Carmen, La Ley, pág. 1036, citada por Vattier Fuenzalida 2000: 19 .

22. Cfr. Carrascosa López y otros 1997: 93.

23. Cfr. Rodríguez de Castro, Eduardo, Informática y derecho, citado por Vattier Fuenzalida 2000: 19.

24. Cfr. Martorell 1997: 637.

25. Fallo de la Corte Suprema de Mendoza (jueza ponente doctora Aída Kemelmajer de Carlucci), citada por Messina de Estrella Gutiérrez 1997: 151.

26. Cfr. Altmark 2001. 
automatizada ${ }^{26}$; que tienen por fin bienes o servicios informáticos, precisando que los bienes informáticos son los elementos materiales que componen el hardware, su unidad de procesamiento, los periféricos, y todos los otros equipos que componen el soporte físico del elemento informático también forman parte de los bienes informáticos, los bienes inmateriales que proporcionan las órdenes, los datos, los procedimientos y las instrucciones en el procesamiento automático de la información; y que los servicios informáticos son aquellos que sirven de apoyo a la informática, como el diseño, el análisis y el mantenimiento del sistema ${ }^{27}$.

En ese mismo orden de ideas, se ha señalado que «existen dos tipos de contratos informáticos fundamentales: aquellos referidos a los bienes (equipos, periféricos, dispositivos, etcétera) y aquellos referidos a los servicios (asistencia, formación, mantenimiento, programas, etcétera)» ${ }^{28}$; que su objeto es, apriorísticamente, la regulación de la actividad informática, precisando, sin embargo, que -sobre la base del Decreto Real Belga del 27 de abril de 1997tales contratos recaen sobre: a) los equipos físicos del sistema de tratamiento de la información (hardware), b) los equipos lógicos (software) y c) la actividad de asesoramiento informático ${ }^{29}$.

La doctrina peruana, siguiendo la noción reseñada que sostiene que los contratos informáticos son aquellos que tienen por objeto bienes o servicios informáticos, enuncia los tipos de contratos informáticos: los contratos de software, como el de licencia de uso de software y el contrato de cesión de derechos de software; los contratos de hardware o de equipos físicos, siendo el de compraventa el más utilizado; los contratos de servicios informáticos, como los de mantenimiento de software o los contratos de consultoría en línea; los contratos de datos informáticos, como los de suministro de información de base de datos; los contratos complejos, como los de outsourcing informático, y el contrato de llave en mano de Internet ${ }^{30}$.

\footnotetext{
27. Cfr. Brizzio 2000: 82.

28. Cfr. Magliona Markovith y López Medel 1999: 29.

29. Cfr. Huerta Miranda y Líbano Manssur 1998: 71-72.

30. Cfr. Núñez Ponce 2008: 37.
} 
Para poder revisar todo el contenido de esta edición, visite nuestra tienda virtual.

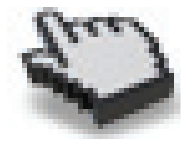

El impacto de las innovaciones tecnológicas en el Derecho Privado

Mfreto F. Soria Aguilar (Compilador)

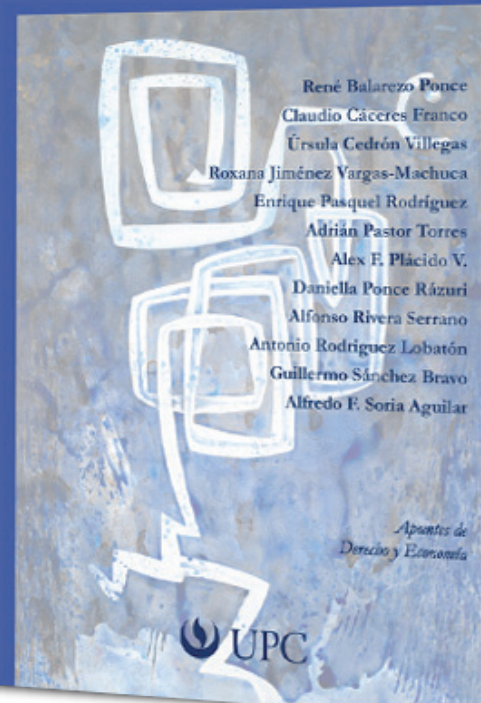

